Prepared for International Journal of Geriatric Psychiatry

Original Research Article

\title{
An evaluation of the additional benefit of population screening for dementia beyond a passive case-finding approach
}

Karen E. Mate ${ }^{a}$, Parker J. Magin ${ }^{b}$, Henry Brodaty ${ }^{c}$, Nigel P. Stocks ${ }^{d}$, Jane Gunne, Peter B.

Disler, John E. Marleya, C. Dimity Pond ${ }^{b}$

${ }^{a}$ School of Biomedical Sciences and Pharmacy, University of Newcastle, NSW, Australia;

${ }^{b}$ School of Medicine \& Public Health, University of Newcastle, NSW, Australia; ' Dementia

Collaborative Research Centre and Centre for Healthy Brain Ageing, School of Psychiatry, University of New South Wales, NSW, Australia; ${ }^{d}$ Discipline of General Practice, School of

Population Health, The University of Adelaide, SA, Australia; ${ }^{2}$ Department of General

Practice The University of Melbourne, Victoria, Australia; fSchool of Rural Health, Monash University, Bendigo VIC, Australia;

\section{Key Points}

- Benefits of population screening for dementia will be overestimated if patients who would have been subjected to case-finding are included in screening studies.

- Most people with dementia could be detected using a case-finding approach

- There is potential for social and economic harm due to the low positive predictive value associated with population screening

- The positive predictive value of a short cognitive assessment (such as the GPCOG) is significantly lower when used as a screening tool, rather than a casefinding tool

Keywords: dementia, screening, case-finding, primary care

Running Title: Case finding or population screening for dementia?

Wordcount: 3,468 (including citations)

*Corresponding Author:

Karen Mate

School of Biomedical Sciences and Pharmacy

University of Newcastle, Callaghan, NSW, Australia, 2308

Phone: +612 49215983; Fax: +61249686727

This is the author manuscript accepted for publication and has undergone full peer review but has not been through the copyediting, typesetting, pagination and proofreading process, which may lead to differences between this version and the Version of Record. Please cite this article as doi: 10.1002/gps.4466

This article is protected by copyright. All rights reserved. 
Email: Karen.Mate@newcastle.edu.au

Support: This project was funded by the Australian National Health and Medical Research Council (Grant ID \#351220 and \#510745)

\section{Abstract}

Objective: General practitioners (GPs) fail to identify more than $50 \%$ of dementia cases using the existing passive case-finding approach. Using data from the "Ageing in General Practice" study, we sought to establish the additional benefit of screening all patients over the age of 75 for dementia beyond those patients already identified by passive case-finding.

Method: Patients were classified as "case-finding" (n=425) or "screening" ( $n=1006)$ based on their answers to four subjective memory related questions or their GP's clinical judgement of their dementia status. Cognitive status of each patient was formally assessed by a research nurse using the Cambridge Cognition Examination (CAMCOG-R). Patients then attended their usual GP for administration of the GP assessment of Cognition (GPCOG) dementia screening instrument, and follow-up care and/or referral as necessary in light of the outcome.

Results: The prevalence of dementia was significantly higher in the case-finding group $(13.6 \%)$ compared to the screening group $(4.6 \%$; $\mathrm{p}<0.01)$. The GPCOG had a positive predictive value (PPV) of $61 \%$ in the case-finding group and 39\% in the screening group; negative predictive value was $>95 \%$ in both groups. GPs and their patients both found the GPCOG to be an acceptable cognitive assessment tool. The dementia cases 
missed via case-finding were younger $(p=0.024)$ and less cognitively impaired $(p=0.020)$ than those detected.

Conclusion: There is a very limited benefit of screening for dementia, as most people with dementia could be detected using a case-finding approach; and considerable potential for social and economic harm due to the low PPV associated with screening.

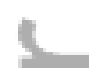

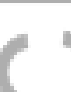
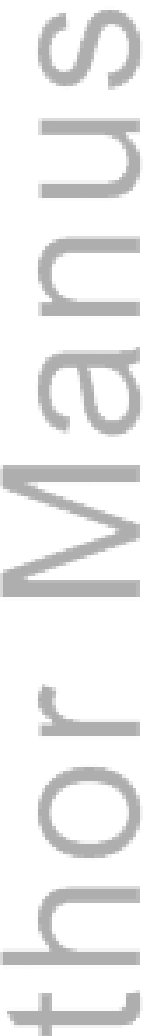

$\left(\frac{10}{20}\right.$

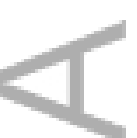

This article is protected by copyright. All rights reserved. 


\section{Introduction}

Primary care physicians (GPs) play an essential role in the recognition and effective ongoing management of dementia, however the diagnosis rate in this setting is only around 50\%, depending on the degree of cognitive impairment (Bradford, et al. 2009; Pentzek, et al. 2009; Pond, et al. 2013). Most patients therefore remain undiagnosed during the early stages of the disease.

Early diagnosis and management of dementia is desired by many patients (Byszewski, et al. 2007; Jha, et al. 2001; Pinner and Bouman 2003), and theoretically has numerous benefits including relief based on better understanding of symptoms, earlier access to medical and social services, an opportunity for fulfilment of short-term goals, and maximised decision-making autonomy for future planning (Dickinson, et al. 2013; Mate, et al. 2012; Phillips J., et al. 2010). Although there is a lack of evidence to confirm that early detection of cognitive decline actually leads to these types of benefits and improvements (Lin, et al. 2013a), there is an increasingly accepted view that a dementia diagnosis should be provided in a 'timely' fashion, that is appropriate for the circumstances of individual patients, rather than any particular disease stage (Brayne, et al. 2007; Dhedhi, et al. 2014).

The detection of dementia has traditionally relied on a "passive" case-finding approach: patients are evaluated for dementia because they or a caregiver bring a memory/cognition concern to their GP, or because their GP raises the issue based on their clinical judgement. In an attempt to improve the recognition of dementia, the UK 
has implemented an "active" case-finding approach, which specifies an opportunistic dementia assessment of 'at-risk' patients based on a number of factors including vascular risk factors, Parkinson's disease and learning disabilities, in addition to subjective memory complaint (National Health Service, 2015). An active case-finding approach, also proposed in the United States (Barnes, et al. 2014), places a greater onus on the health system to search systematically for 'at risk' people, rather than waiting for them to present with symptoms or signs of disease (Ruf and Morgan 2008). Whilst a case-finding approach to identification of dementia (either active or passive) is currently endorsed by Royal Australian College of General Practitioners (RACGP, 2012), the US Preventative Services task Force (Lin, et al. 2013b), and the UK National Health Service (National Health Service, 2015), routine screening of all older people has also been proposed as a method to improve the recognition of dementia (Ashford, et al. 2007).

Screening involves testing of an asymptomatic population to increase early detection and treatment of the disease, in order to reduce morbidity or mortality (Maxim, et al. 2014). Well established and widely endorsed general criteria can be used to assess whether screening for a particular condition will be feasible and beneficial (Wilson and Junger 1968), but there is considerable disagreement and debate on whether dementia fulfils these criteria (Ashford et al. 2007; Le Couteur, et al. 2013). The major areas of debate include establishing agreed guidelines for management of identified cases and whether adequate facilities exist for diagnosis and treatment following positive screening, and the lack of a curative treatment. Screening for dementia may increase 
case identification (Borson, et al. 2007; Eichler, et al. 2015) but fail to improve subsequent management of patients or their health outcomes (Boustani, et al. 2003).

One of the major problems associated with population screening for dementia is associated with the comparatively low prevalence of the disease encountered in general practice; the positive predictive value (ie percentage of true positives in the abnormal range on the tool) of any cognitive assessment tool is therefore likely to be lower (that is, produce a higher percentage of false positives) than in higher prevalence settings such as memory clinics. A false positive result can result in needless anxiety for the patient, as well as costly further testing and referral. Other arguments against screening include reports from GPs of limited time, lack of known cure, suitability of screening tools and the distress and costs associated with investigations for dementia (Brodaty, et al. 1994; Gaboreau, et al. 2014; Le Couteur et al. 2013). Although evidence is limited, findings suggest that screening for dementia has limited acceptance amongst the general public and health care professionals (Martin, et al. 2015).

The balance of harms and benefits arising from dementia screening should be considered in the context of pre-existing case-finding, which already happens independently of a screening program. The positive predictive value of screening that includes patients who would have been subject to case-finding anyway will tend to overestimate the benefit of screening. In this analysis of data from the "Ageing in General Practice" (AGP) study, we sought to establish the additional utility of dementia screening (beyond that of case-finding) in patients over the age of 75 . 


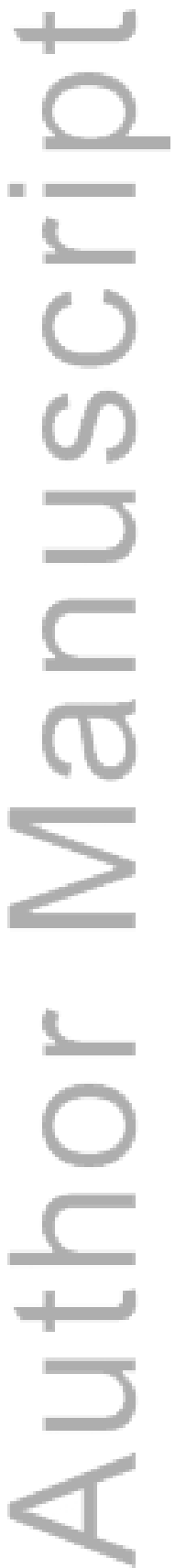

This article is protected by copyright. All rights reserved. 


\section{Method}

\section{Study Population}

This study utilises baseline data collected from intervention GPs and their patients during the "Ageing in General Practice" (AGP) study. The methodology is described in detail elsewhere (Pond, et al. 2012). Briefly, recruitment was initiated in 2007 across five Australian sites: Newcastle (NSW), Sydney (NSW), Melbourne (Victoria), Adelaide (South Australia), Bendigo (Victoria). General practices within a 30km catchment area of each study site were identified, listed in a random order and approached sequentially to participate. Practices were allocated in a ratio of 2:1 to an intervention or waitlist group, using an independently generated allocation schedule (Pond et al. 2012). The analysis described here utilises data from the intervention group only; GPs in this group tested their patients' cognitive status using the General Practitioner Assessment of Cognition (GPCOG), as described below.

The procedure was that participating GPs mailed an invitation to participate to their English speaking patients (aged 75 years or over). Patients were excluded from the invitation if they resided in an aged care facility, or had been diagnosed with Parkinson's disease, multiple sclerosis, motor neuron disease, central nervous system inflammation, psychotic symptoms, progressive malignancy or a developmental disability.

A list of consenting patients was compiled for each GP, who then completed an audit that included their clinical judgement (informed by knowledge of the patient and 
recourse to the patient's clinical notes) of each patient's dementia status using one of four options: "No Dementia", "Possible Dementia", "Probable Dementia” or "Definite Dementia". Patients classified as having "Definite Dementia" were excluded from the current analysis.

\section{Data Collection}

Participants were interviewed in their own home by a research nurse, with their responses recorded directly onto a computerised database. The following information was utilised for this study.

Demographic data: Gender, age and postcode were recorded. Postcode was used as an indicator of socioeconomic status using the ranks of the Index of Relative Socioeconomic Advantage and Disadvantage (IRSAD), a continuous variable of advantage (high values) to disadvantage (low values) (Australian Bureau of Statistics, 2006).

Cognitive function: was assessed at baseline using the CAMCOG-R subsection of the Cambridge examination for mental disorders of the elderly (CAMDEX; (Roth, et al. 1998), initially validated in the UK. A cut-point of 79/80 differentiates between demented and non-demented individuals with $93 \%$ sensitivity and $87 \%$ specificity (Huppert, et al. 1996), and was therefore used as an indicator of dementia for the purposes of this study.

Quality of Life: was assessed at baseline and 12 months using the WHOQOL-BREF a widely used quality of life instrument, validated for use in the Australian population (Hawthorne, et al. 2006). 
Depression: was assessed at baseline and 12 months using the Geriatric Depression Scale (GDS-15), which has been validated and widely used in primary health care research (Sheikh and Yesavage 1986). For this study, a cut point of $>5$ was indicative of possible depression, and $>10$ was indicative of definite depression.

\section{Case-finding and Screening}

The AGP study provided an opportunity to investigate the difference in utility between a passive case-finding and a population screening approach. The intervention arm of the AGP was designed so that patients could be classified as case-finding or screening, based on a (i) a number of questions to identify patients with a memory/cognition concern, and their disclosure of this (or intent to disclose) to their GP, and (ii) a GP audit to identify patients with possible or probable dementia based on the clinical judgement of their GP. The following 4 questions were included in the patient interview, performed by the research nurse:

1. Do you have any complaints about your memory?

2. Have you mentioned these to you GP?

3. If not, have you been intending to tell your GP?

4. Have you sought treatment or taken any remedies such as herbal medications or vitamins specifically for you memory? Please give details.

If questions 2, 3 or 4 were answered in the affirmative, the patient was considered as "case-finding". An affirmative answer to Q1only, i.e. patients with no intention to disclose or discuss their memory complaint with their GP, did not warrant classification as case-finding. Patients identified as having possible or probable dementia on the GP 
baseline audit, based on GP clinical judgement (that is, knowledge of the patient plus recourse to their clinical notes), were also considered as case-finding. This constitutes a passive rather than active case finding approach, as there was no attempt to identify "atrisk" patients based on other relevant parameters (e.g. vascular risk, learning disabilities). Hereafter, our use of 'case-finding' refers to passive case-finding. All other patients were considered as "screening" patients; that is, patients who, outside this study, would not receive a cognitive function test unless the GP decided to screen all patients aged over a certain age. They thus represent the source of additional potential benefit or harms of screening over case-finding. Patients with an existing dementia diagnosis were not included in the study.

\section{Administration and Evaluation of the GPCOG}

Within two weeks of their baseline home interview, patients attended their usual GP for administration of the GPCOG dementia screening instrument (Brodaty, et al. 2002), and follow-up care and/or referral as necessary in light of the outcome. The GPCOG consists of two sections, the GPCOG-patient (scored out of 9) and the GPCOG-informant (scored out of 6). The GPCOG-informant is performed only for patients who score 5-8 on the GPCOG-patient, and imputed (as 6/6) for those that score 9/9 on the GPCOG-patient. The two sections were combined to give a total score out of 15 , with $<9$ indicative of likely cognitive impairment. The GPCOG is suited to use in general practice because of its brevity, psychometric properties and its use of informant report in borderline cases (Brodaty, et al. 2004; Milne, et al. 2008). 
After the GPCOG was administered, patients were handed a paper survey on the acceptability of the screening instrument and procedures, and a reply paid envelope to return the completed survey to the study site. GPs were also asked to rate the acceptability of the GPCOG using an anonymous paper based survey, returned by reply paid envelope.

Statistical Analyses

Characteristics of patients in the case-finding and screening groups at baseline were compared using Students $t$-test for continuous variables and chi-square statistic for categorical variables. The performance of the GPCOG in the case finding and screening groups was examined using the CAMCOG-R to classify participants as having or not having dementia.

Positive predictive value (PPV) of the GPCOG in our case finding and screening groups were primary outcomes. PPV expresses the proportion of patients with a positive test result who actually have the disease. There are significant potential harms associated with a false positive result for dementia (eg patient distress, inappropriate testing and referrals) and we also anticipated low prevalence of dementia in our study populations. Negative predictive values (NPVs), the proportion of patients with a negative test result that are actually disease free, were secondary outcomes. NPV (a measure of false negative results) is of lesser clinical significance than PPV in this context, as there is currently no curative dementia treatment available. PPV and NPV of the GPCOG in casefinding and screening groups were compared using Z-tests. 
Sensitivity and specificity of the GPCOG in the case-finding and screening groups were calculated, and then compared using Fisher's exact test. The areas under the curve (AUC) in the ROC curves in the case-finding and screening groups were calculated and then compared using z-test at VassarStats:Website for Statistical Comparison (www.vassarstats.net/index.html). All other analyses were conducted using SPSS (v22). Survey responses regarding the acceptability of the GPCOG were analysed descriptively. $=$ A post-hoc analysis (using Students $t$-test for continuous, and chi-square statistic for categorical variables) compared demographics of the true positives and false negatives in the case finding group.

\section{Ethics approval}

The Human Ethics Committees of the University of Newcastle, University of NSW, The University of Melbourne, University of Adelaide and Monash University approved the study protocol. All GPs and patients provided written informed consent. 


\section{Results}

Of the 1,431 patients that entered the study (20\% response rate), 425 were considered to be case-finding based on their answers to the memory related questions in the baseline interview and/or their GPs' clinical judgement of their dementia status. The remaining 1006 patients constituted the screening group. The gender and socioeconomic characteristics of the two groups were similar, however there were marked differences in other areas (Table 1). CAMCOG-R dementia prevalence in the case-finding group (13.6\%) was almost three times higher than in the screening group (4.6\%), reflected in the significantly lower CAMCOG scores in the case-finding group $(\mathrm{p}<0.001)$. The prevalence of possible depression (GDS score $>5$ ) was two times higher in the case-finding group (11.5\%) compared to the screening group (5.6\%; $\mathrm{p}<0.001)$, however, the prevalence of definite depression (GDS score $>10$ ) was the same $(0.2 \%)$ in both groups. Physical, psychological and environmental quality of life were all significantly lower in the case-finding group compared to the screening group (all $\mathrm{p}<0.001$; Table 1).

A GP-administered GPCOG was completed for 283 (66.6\%) case-finding patients and $672(66.8 \%)$ screening patients. The positive predictive value (PPV) of the GPCOG was higher in the case-finding group (0.61) than the screening group $(0.39 ; \mathrm{p}<0.01)$. The negative predictive value (NPV) of the GPCOG was $>95 \%$ in both groups. ROC curve analyses found no significant difference between the AUCs in the two groups $(Z=0.513$; $\mathrm{p}=0.6$ ). Sensitivity of the GPCOG was higher, but not significantly so, in the case-finding group (0.69 cf. $0.45 ; p=0.15)$. 
Case-finding patients with dementia that were not identified using the GPCOG (false negatives), were on average four years younger $(\mathrm{p}=0.024)$ and scored on average 6 points higher on the CAMCOG-R $(\mathrm{p}=0.020)$ than those patients correctly identified with dementia (true positives) (Table 3).

More than $90 \%$ of the GPs $(n=71)$ found the GPCOG to be acceptable to their patients, practical and viable to use in the general practice setting (Figure 1). There was no difference between the case-finding and screening groups in the patient ratings of GPCOG acceptability (Figure 2).

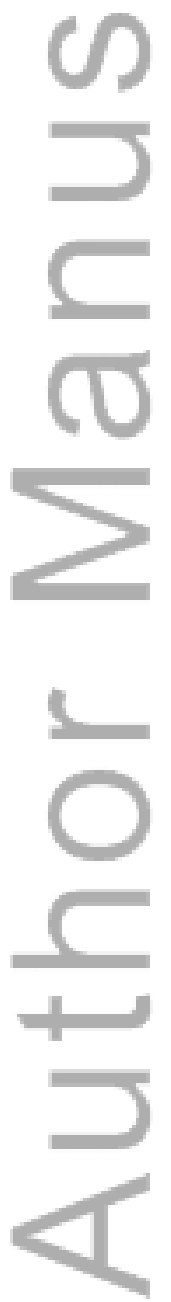

This article is protected by copyright. All rights reserved. 


\section{Discussion}

\section{Summary of Findings}

This is the first study to compare the difference in detection rates for dementia in general practice utilising either a case-finding or screening approach. A case-finding approach, using the GPCOG as a cognitive assessment tool, resulted in a significantly higher PPV than a screening approach using the same tool. The marked difference can be attributed to the higher prevalence of dementia in the case-finding patients compared to those that were screened. The GPCOG was acceptable to both GPs and patients, and is therefore a useful and effective tool to assist GPs in their implementation of a case-finding approach. Cases of dementia that were missed in the case finding group (that is, the false negatives) were younger and less impaired than those correctly recognised.

\section{Relevance of Findings}

Our findings illustrate the importance of careful selection of both an appropriate assessment method, and the population to be tested; a screening test with high sensitivity and specificity can result in a low PPV if the prevalence of the condition is low. Screening tools function differently in different clinical populations, and therefore must be validated and refined in the setting that it will be used; performance in specialist (typically high prevalence) settings cannot be directly extrapolated to primary care (typically low prevalence) settings. The lower PPV of the GPCOG when used as a screening tool, rather than a case-finding tool, increased the number of false positives results, potentially leading to further unnecessary testing with both economic and social 
consequences. This provides further support for the argument that case-finding will produce fewer false positives than screening (Boustani et al. 2003; Patterson, et al. 2001).

Evidence is limited concerning the actual benefits and harms associated with screening for dementia or adverse effects of a false-positive result (Lin et al. 2013b). It is essential that future studies in this area should take into account the case-finding approach currently used in primary care in order to provide an accurate measure of the additional benefit of screening. Although previous studies have reported that screening can increase dementia identification by up to 40\% (Borson et al. 2007; Eichler et al. 2015), they did not take into account those patients who would have been subject to case-finding anyway, thereby overestimating the benefit of screening. It is the marginal benefit of screening (i.e. the benefit in patients proposed to be screened but would who not have already been subject to case-finding) that is most relevant. For example, patients with a subjective memory complaint, part of the criteria used to define the case-finding group in this study, are 2.5 times more likely to have dementia (Pond et al. 2013); or in other words, a higher pre-test probability of having dementia. The removal of these patients (who would have been subject to case-finding) from the screening pool, decreases the pre-test probability, and therefore reduces the positive predictive value of any screening test for dementia.

Our study suggests that refinements to a case-finding approach, based on clinical, patient and family concerns, has greater potential than screening to provide a timely, and patient-focussed diagnosis of dementia. The relatively high PPV of the GPCOG in our 
'passive case-finding' population makes it an appropriate cognitive assessment tool to improve the case-finding approach in a general practice setting, and to determine whether further investigations or referrals are warranted. A short questionnaire to screen for dementia is theoretically acceptable to most patients (Braun, et al. 2014; Magin P., et al. 2015), and the GPCOG was well accepted by both GPs and patients as a suitable tool for checking memory in this study. Modifications and refinements to the case-finding approach and/or tools used, should pay particular attention to younger and less impaired patients, as they are more likely to receive a false negative result. A case-finding approach to identification of dementia also favours a timely (that is, at the right time for the individual), rather than early diagnosis of dementia, as it places the onus on the patient (or carer) to present with a concern. Depending upon individual circumstances, a premature diagnosis of dementia, in the absence of an effective treatment, may cause harm, including consequences in health insurance policies, diminution of control in financial and other decision making, feeling of loss, anger and frustration, and loss of social standing(Bunn, et al. 2012; Dhedhi et al. 2014). In the absence of a treatment that modifies the course of the disease, the clinical implications are that an early rather than timely diagnosis confers little advantage to the patient. If the GP is aware of a possible or probable memory problem, the patient can be managed with appropriate communication and risk management strategies, prescribing practice and service referrals until a formal diagnosis is desired.

Limitations

This article is protected by copyright. All rights reserved. 
Case finding patients were identified based on their answers to four questions asked by the research nurse, rather than presenting to the GP with a memory concern. The study therefore represents a modelling of case-finding, rather than an assessment of the casefinding approach as it would perform in practice. In addition, ideally the test used for benchmarking the effectiveness of a screening test should have sensitivity and specificity of $100 \%$. The psychometric properties of currently available instruments, including the CAMCOG-R is therefore a limitation; the cut-off point of 79/80 on the CAMCOG used in this study is indicative of dementia with $93 \%$ sensitivity and $87 \%$ specificity (Huppert et al. 1996). Although the CAMCOG is a significant predictor for the clinical diagnosis of dementia (van Hout, et al. 2001), most cases require additional clinical judgment for a definitive diagnosis.

\section{Conclusions}

The benefits of population screening for dementia will be overestimated if patients who would have been subjected to case-finding are included in screening studies. Due to the different prevalence of dementia in case-finding and screening patients, the positive predictive value of a short cognitive assessment (such as the GPCOG) is significantly lower when used as a screening tool, rather than a case-finding tool. The potential for harm resulting from a false positive test for dementia will therefore be greater with screening compared to case-finding. In light of these findings, refinement to the casefinding approach offers the best opportunity for timely recognition of dementia in primary care. 


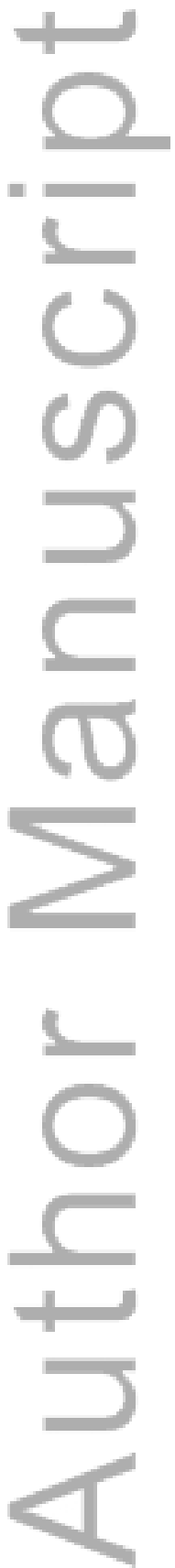

This article is protected by copyright. All rights reserved. 


\section{References}

Ashford JW, Borson S, O'Hara R, Dash P, Frank L, Robert P, Shankle WR, Tierney MC, Brodaty H, Schmitt FA, et al. 2007 Should older adults be screened for dementia? It is important to screen for evidence of dementia! Alzheimer's \& Dementia 3 75-80.

Australian Bureau of Statistics 2006 Census of Population and Housing: Socio-Economic Indexes for Areas (SEIFA), Australia (ABS Cat. No. 2033.0.55.001). Canberra: ABS.

Barnes DE, Beiser AS, Lee A, Langa KM, Koyama A, Preis SR, Neuhaus J, McCammon RJ, Yaffe K, Seshadri S, et al. 2014 Development and validation of a brief dementia screening indicator for primary care. Alzheimer's \& Dementia 10 656-665.

Borson S, Scanlan J, Hummel J, Gibbs K, Lessig M \& Zuhr E 2007 Implementing routine cognitive screening of older adults in primary care: process and impact on physician behavior. J Gen Intern Med 22 811-817.

Boustani M, Peterson B, Hanson L, Harris R \& Lohr K 2003 Screening for Dementia in Primary Care: A Summary of the Evidence for the U.S. Preventive Services Task Force. Annals of Internal Medicine 138 927-937.

Bradford A, Kunik ME, Schulz P, Williams SP \& Singh H 2009 Missed and delayed diagnosis of dementia in primary care: prevalence and contributing factors. Alzheimer Disease \& Associated Disorders 23 306-314.

Braun SR, Reiner K, Tegeler C, Bucholtz N, Boustani MA \& Steinhagen-Thiessen E 2014 Acceptance of and attitudes towards Alzheimer's disease screening in elderly German adults. Int Psychogeriatr 26 425-434.

Brayne C, Fox C \& Boustani M 2007 Dementia screening in primary care: is it time? JAMA 298 2409-2411.

Brodaty H, Howarth GC, Mant A \& Kurrle SE 1994 General practice and dementia. A national survey of Australian GPs. Medical Journal of Australia 160 10-14.

Brodaty H, Kemp NM \& Low LF 2004 Characteristics of the GPCOG, a screening tool for cognitive impairment. Int J Geriatr Psychiatry 19 870-874.

Brodaty H, Pond D, Kemp NM, Luscombe G, Harding L, Berman K \& Huppert FA 2002 The GPCOG: a new screening test for dementia designed for general practice. Journal of the American Geriatrics Society $\mathbf{5 0}$ 530-534.

Bunn F, Goodman C, Sworn K, Rait G, Brayne C, Robinson L, McNeilly E \& Iliffe S 2012 Psychosocial factors that shape patient and carer experiences of dementia diagnosis and treatment: a systematic review of qualitative studies. PLoS Med 9 e1001331.

Byszewski AM, Molnar FJ, Aminzadeh F, Eisner M, Gardezi F \& Bassett R 2007 Dementia diagnosis disclosure: A study of patient and caregiver perspectives. Alzheimer Disease and Associated Disorders 21 107-114.

Dhedhi SA, Swinglehurst D \& Russell J 2014 'Timely' diagnosis of dementia: what does it mean? A narrative analysis of GPs' accounts. BMJ Open4:e004439. doi:10.1136/bmjopen-2013004439 http://bmjopen.bmj.com/content/4/3/e004439.full.pdf+html Accessed 24 0ct 2014.

Dickinson C, Bamford C, Exley C, Emmett C, Hughes J \& Robinson L 2013 Planning for tomorrow whilst living for today: the views of people with dementia and their families on advance care planning. International Psychogeriatrics 25 2011-2021.

Eichler T, Thyrian JR, Hertel J, Michalowsky B, Wucherer D, Dreier A, Kilimann I, Teipel S \& Hoffman W 2015 Rates of formal diagnosis of dementia in primary care: The effect of screening. Alzheimer's \& Dementia: Diagnosis, Assessment \& Disease Monitoring 1 87-93. 
Gaboreau Y, Imbert P, Jacquet JP, Paumier F, Couturier P \& Gavazzi G 2014 Factors affecting dementia screening by general practitioners in community-dwelling elderly populations: a large cross-sectional study in 2 areas of France. Alzheimer Disease and Associated Disorders 28 58-64.

Hawthorne G, Herrman H \& Murphy B 2006 Interpreting the WHOQOL-BREF: preliminary population norms and effect sizes. Social Indicators Research 77 37-59.

Huppert FA, Jorm AF, Brayne C, Girling DM, Barkley C, Beardsall L \& Paykel ES 1996 Psychometric properties of the CAMCOG and its efficacy in the diagnosis of dementia. Aging, Neuropsychology and Cognition 3 201-214.

Jha A, Tabet N \& Orrell M 2001 To tell or not to tell-comparison of older patients' reaction to their diagnosis of dementia and depression. Int J Geriatr Psychiatry 16 879-885.

Le Couteur DG, Doust J, Creasey H \& Brayne C 2013 Political drive to screen for pre-dementia: not evidence based and ignores the harms of diagnosis. BMJ $347 \mathrm{f} 5125$.

Lin JS, O'Connor E, Rossom RC, Perdue LA \& Eckstrom E 2013a Screening for cognitive impairment in older adults: A systematic review for the U.S. Preventive Services Task Force. Ann Intern Med 159 601-612.

Lin JS, O'Connor E, Rossom RC, Perdue LA \& Eckstrom E 2013b Screening for cognitive impairment in older adults: A systematic review for the U.S. Preventive Services Task Force. Annals of Internal Medicine 159 601-612.

Magin P, Juratowitch L, Dunbabin J, McElduff P, Goode S, Tapley A \& Pond D 2015 Attitudes to Alzheimer's disease testing of Australian general practice patients: a cross-sectional questionnaire-based study. Int J Geriatr Psychiatry doi: 10.1002/gps.4335

Martin S, Kelly S, Khan A, Cullum S, Dening T, Rait G, Fox C, Katona C, Cosco T, Brayne C, et al. 2015 Attitudes and preferences towards screening for dementia: a systematic review of the literature. BMC Geriatr 1566.

Mate KE, Pond CD, Magin PJ, Goode SM, McElduff P \& Stocks NP 2012 Diagnosis and disclosure of a memory problem is associated with quality of life in community based older Australians with dementia. Int Psychogeriatr 24 1962-1971.

Maxim LD, Niebo R \& Utell MJ 2014 Screening tests: a review with examples. Inhalation Toxicology 26 811-828.

Milne A, Culverwell A, Guss R, Tuppen J \& Whelton R 2008 Screening for dementia in primary care: a review of the use, efficacy and quality of measures. Int Psychogeriatr 20 911-926.

National Health Service, England NHS 2015 Enhanced Service Speification. Facilitating timely diagnosis and support for people with dementia 2015/6. Available at:

https://www.england.nhs.uk/commissioning/wpcontent/uploads/sites/12/2015/03/facilitate-tmly-diag-dementia.pdf

Patterson C, Gauthier S, Bergman H, Cohen C, Feightner JW, Feldman H, Grek A \& Hogan DB 2001 The recognition, assessment and management of dementing disorders: conclusions from the Canadian Consensus Conference on Dementia. The Canadian Journal of Neurological Sciences 28 Suppl 1 S3-16.

Pentzek M, Wollny A, Wiese B, Jessen F, Haller F, Maier W, Riedel-Heller SG, Angermeyer MC, Bickel H, Mosch E, et al. 2009 Apart from nihilism and stigma: what influences general practitioners' accuracy in identifying incident dementia? American Journal of Geriatric Psychiatry 17 965-975.

Phillips J., Pond D. \& Shell A. 2010 No time like the present: the importance of a timely dementia diagnosis, Alzheimer's Australia. Available at http://www.fightdementia.org.au/common/files/NAT/20100900 Nat QDC QDC7NTLTP.pdf 
Pinner G \& Bouman WP 2003 Attitudes of patients with mild dementia and their carers towards disclosure of the diagnosis. International Psychogeriatrics 15 279-288.

Pond C, Brodaty H, Stocks N, Gunn J, Marley J, Disler P, Magin P, Paterson N, Horton G, Goode S, et al. 2012 Ageing in general practice (AGP) trial: a cluster randomised trial to examine the effectiveness of peer education on GP diagnostic assessment and management of dementia. BMC Family Practice 1312.

Pond CD, Mate KE, Phillips J, Stocks NP, Magin PJ, Weaver N \& Brodaty H 2013 Predictors of agreement between general practitioner detection of dementia and the revised Cambridge Cognitive Assessment (CAMCOG-R). Int Psychogeriatr 25 1639-1647.

Roth M, Huppert FA, Mountjoy CQ \& Tym E 1998 CAMDEX-R: The Cambridge examination for mental disorders of the elderly - revised. Cambridge: Cambridge University Press.

Royal Australian College of General Practice 2012 Guidelines for preventative activities in general practice, 8th edition. East Melbourne, Vic. Australia: Royal Australian College of General Practice.

Ruf M \& Morgan 02008 Diagnosis and screening. In Public Health Textbook. England: Public Health Action Support Team.

Sheikh JI \& Yesavage JA 1986 Geriatric Depression Scale (GDS): Recent evidence and development of a shorter version. In Clinical Gerontology: A Guide to Assessment, pp 165-173. Ed TL Brink. New York: Haworth Press.

van Hout H, Teunisse S, Derix M, Poels P, Kuin Y, Vernooij-Dassen M, Grol R \& Hoefnagels W 2001 CAMDEX, can it be more efficient? Observational study on the contribution of four screening measures to the diagnosis of dementia by a memory clinic team. Int J Geriatr Psychiatry 16 64-69.

Wilson J \& Junger C 1968 Principles and practice of screening for disease: World Health Organization Public Health Paper 34. Geneve: World Health Organization.

This article is protected by copyright. All rights reserved. 


\section{Competing Interests}

CDP and HB have sat on advisory boards for Pfizer, Novartis, Janssen, Lundbeck and Nutricia, and been speakers sponsored by Pfizer, Novartis (HB only) and Janssen (HB only). HB has been an investigator on projects funded by Pfizer, Novartis, Janssen, Lundbeck, Lilly and Sanofi, and acted as a consultant for Merck and Baxter. All other authors have no competing interests to declare.

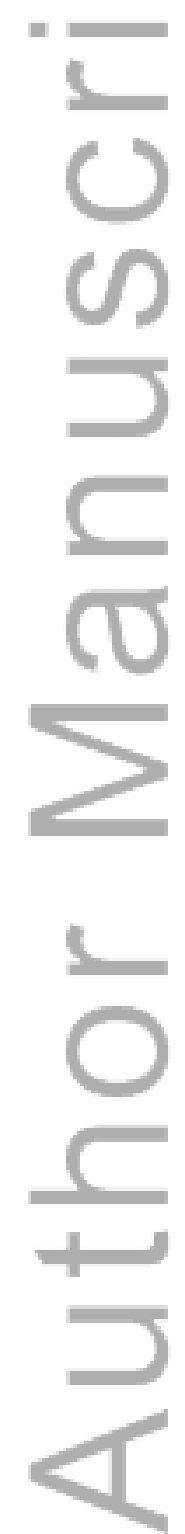

This article is protected by copyright. All rights reserved. 
Table 1 Characteristics of case-finding and screening patients

\begin{tabular}{lccc}
\hline & Case-finding & Screening & p-value \\
\hline $\begin{array}{l}\text { Patient } \\
\text { characteristics }\end{array}$ & $\mathbf{n = 4 2 5}$ & $\mathbf{n = 1 0 0 6}$ & \\
\hline Gender & & & \\
\hline Male & $45.4 \%$ & $45.7 \%$ & \\
\hline Female & $54.6 \%$ & $54.3 \%$ & 0.477 \\
\hline Age (years) & $81.66 \pm 4.39$ & $81.13 \pm 4.15$ & 0.037 \\
\hline IRSAD & $6.96 \pm 2.56$ & $7.08 \pm 2.54$ & 0.440 \\
\hline Education: & & & \\
\hline No School Certificate & $15.6 \%$ & $12.2 \%$ & \\
\hline Secondary & $71.3 \%$ & $71.1 \%$ & \\
\hline Tertiary & $13.0 \%$ & $16.7 \%$ & 0.128 \\
\hline CAMCOG score & $87.79 \pm 9.13$ & $91.53 \pm 6.29$ & $<0.001$ \\
\hline CAMCOG dementia & $13.6 \%$ & $4.6 \%$ & $<0.001$ \\
\hline GDS Score & $2.61 \pm 2.35$ & $1.87 \pm 1.92$ & $<0.001$ \\
\hline GDS Depression & $11.5 \%$ & $5.6 \%$ & $<0.001$ \\
\hline WHOQoL - BREF: & \multicolumn{3}{l}{} \\
\hline Physical & $66.68 \pm 15.11$ & $70.64 \pm 14.81$ & $<0.001$ \\
\hline Psychological & $67.38 \pm 12.40$ & $72.39 \pm 12.29$ & $<0.001$ \\
\hline Social & $78.05 \pm 13.39$ & $79.11 \pm 13.20$ & 0.205 \\
\hline Environmental & $77.91 \pm 12.24$ & $81.86 \pm 10.78$ & $<0.001$ \\
\hline
\end{tabular}

a Index of relative socioeconomic advantage and disadvantage

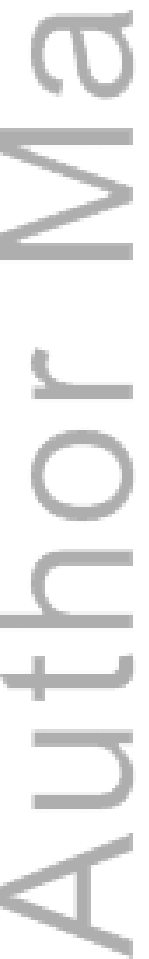

This article is protected by copyright. All rights reserved. 
Table 2 Performance of the GP administered GPCOG against the CAMCOG, when used as casefinding or screening tool

\begin{tabular}{|c|c|c|}
\hline Properties & $\begin{array}{c}\text { Case-finding } \\
(n=283)\end{array}$ & $\begin{array}{c}\text { Screening } \\
(n=672)\end{array}$ \\
\hline Positive Predictive Value & 0.61 & 0.39 \\
\hline Negative Predictive Value & 0.96 & 0.98 \\
\hline Sensitivity & 0.69 & 0.45 \\
\hline Specificity & 0.96 & 0.98 \\
\hline Misclassification Rate $^{a}$ & $8.4 \%$ & $3.7 \%$ \\
\hline Area Under Curve & 0.815 & 0.780 \\
\hline 95\% Confidence interval & $0.725-0.905$ & $0.672-0.888$ \\
\hline Standard Error & 0.046 & 0.055 \\
\hline
\end{tabular}

a The proportion of participants incorrectly categorised by the test: (false positives + false negatives)/total number of participants.

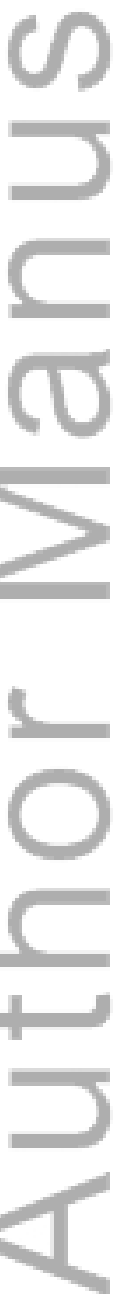

This article is protected by copyright. All rights reserved. 
Table 3 A comparison of people with dementia that were identified or missed using a casefinding approach and the GPCOG.

\begin{tabular}{lccc}
\hline $\begin{array}{l}\text { Patient } \\
\text { Characteristics }\end{array}$ & $\begin{array}{c}\text { True positives } \\
(\mathbf{n = 2 2})\end{array}$ & $\begin{array}{c}\text { False Negatives } \\
(\mathbf{n = 1 0 )}\end{array}$ & P value \\
\hline Gender & & & \\
\hline Male & $61.9 \%$ & $30.0 \%$ & \\
\hline Female & $38.1 \%$ & $70.0 \%$ & 0.202 \\
\hline Age (years) & $84.76 \pm 4.78$ & $80.50 \pm 4.38$ & 0.024 \\
\hline IRSAD & $7.65 \pm 2.41$ & $7.40 \pm 1.90$ & 0.777 \\
\hline CAMCOG score & $69.10 \pm 10.03$ & $75.50 \pm 4.40$ & 0.020 \\
\hline GDS Score & $3.20 \pm 2.80$ & $2.90 \pm 2.38$ & 0.774 \\
\hline WHOQoL -BREF: & & & \\
\hline Physical & $23.65 \pm 3.48$ & $23.80 \pm 4.83$ & 0.925 \\
\hline Psychological & $21.47 \pm 3.02$ & $21.00 \pm 3.06$ & 0.700 \\
\hline Social & $12.64 \pm 1.28$ & $12.38 \pm 1.30$ & 0.644 \\
\hline Environmental & $79.86 \pm 10.84$ & $73.96 \pm 9.63$ & 0.179 \\
\hline
\end{tabular}

This article is protected by copyright. All rights reserved. 


\section{University Library}

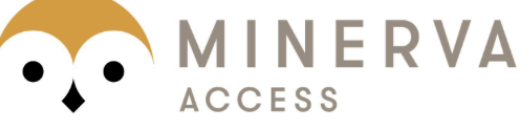

A gateway to Melbourne's research publications

Minerva Access is the Institutional Repository of The University of Melbourne

Author/s:

Mate, KE;Magin, PJ;Brodaty, H;Stocks, NP;Gunn, J;Disler, PB;Marley, JE;Pond, CD

Title:

An evaluation of the additional benefit of population screening for dementia beyond a passive case-finding approach

Date:

2017-03-01

\section{Citation:}

Mate, K. E., Magin, P. J., Brodaty, H., Stocks, N. P., Gunn, J., Disler, P. B., Marley, J. E. \& Pond, C. D. (2017). An evaluation of the additional benefit of population screening for dementia beyond a passive case-finding approach. INTERNATIONAL JOURNAL OF GERIATRIC PSYCHIATRY, 32 (3), pp.316-323. https://doi.org/10.1002/gps.4466.

Persistent Link:

http://hdl.handle.net/11343/291056 